Georgia State University

ScholarWorks @ Georgia State University

\title{
Workplace Bullying, Perceived Job Stressors, and Psychological Distress: Gender and Race Differences in the Stress Process
}

Brandon K. Attell

Kiersten Kummerow Brown

Linda A. Treiber

Follow this and additional works at: https://scholarworks.gsu.edu/ghpc_articles

\section{Recommended Citation}

Attell, Brandon K.; Brown, Kiersten Kummerow; and Treiber, Linda A., "Workplace Bullying, Perceived Job Stressors, and Psychological Distress: Gender and Race Differences in the Stress Process" (2017). GHPC Articles. 168.

https://scholarworks.gsu.edu/ghpc_articles/168

This Article is brought to you for free and open access by the Georgia Health Policy Center at ScholarWorks @ Georgia State University. It has been accepted for inclusion in GHPC Articles by an authorized administrator of ScholarWorks @ Georgia State University. For more information, please contact scholarworks@gsu.edu. 


\title{
Workplace bullying, perceived job stressors, and psychological distress: Gender and race differences in the stress process
}

\author{
Brandon K. Attell ${ }^{\text {a, }}{ }^{*}$, Kiersten Kummerow Brown ${ }^{\mathrm{b}}$, Linda A. Treiber ${ }^{\mathrm{c}}$ \\ ${ }^{a}$ Georgia Health Policy Center, Georgia State University, P.O. Box 3992, Atlanta, GA 30302-5020, USA \\ b Department of Sociology, Georgia State University, Langdale Hall 1061, P.O. Box 5020, Atlanta, GA 30302-5020, USA \\ ${ }^{c}$ Department of Sociology and Criminal Justice, Kennesaw State University, 402 Bartow Ave. NW, Social Science Building, Room 4070, \\ Kennesaw, GA 30144, USA
}

\section{A R T I C L E I N F O}

\section{Article history:}

Received 31 August 2016

Received in revised form 27 December 2016

Accepted 9 February 2017

Available online $\mathrm{xxx}$

\section{Keywords:}

Workplace bullying

Gender

Race

Stress process

Anxiety

Hopelessness

\begin{abstract}
A B S T R A C T
A large body of empirical research documents the adverse mental health consequences of workplace bullying. However, less is known about gender and race differences in the processes that link workplace bullying and poor mental health. In the current study, we use structural equation modeling of survey data from the 2010 Health and Retirement Study $(\mathrm{N}=2292)$ and draw on stress process theory to examine coworker support as a buffering mechanism against workplace bullying, and gender and race differences in the relationships between bullying and psychological distress. The results of the analysis indicate that coworker support serves as a protective buffer against workplace bullying, although the buffering effect is relatively small. We also find that the effects of workplace bullying more heavily impact women and persons of color. Specifically, women and African American individuals in our sample were less protected from the buffering mechanism of co-worker social support.
\end{abstract}

() 2017 Elsevier Inc. All rights reserved.

\section{Introduction}

Once considered a phenomenon occurring at school in early childhood and adolescence, a large body of literature now demonstrates the substantial prevalence of bullying at the workplace during adulthood (Einarsen et al., 2004; Einarsen et al., 2011; Rayner, 1997; Rayner and Hoel, 1997; Rayner et al., 2002; Zapf and Einarsen, 2001). Workplace bullying broadly refers to ongoing negative acts directed at individuals in hostile work environments through perceived power imbalances in employee relationships (Salin, 2003a). In a recent nationally representative sample of adult Americans, 35\% of respondents experienced bullying firsthand at work (Namie, 2010). Experiences of bullying at work occur across all job positions and educational levels of workers, although there are noted gender and racial disparities for women and persons of color (Escartín et al., 2012).

The consequences of workplace bullying directly impact employees and the organizations for which they work. Victims of bullying at work experience increased risk of poor physical and mental health, including measures of cardiovascular disease, post-traumatic stress, and depression (Kivimäki et al., 2003; Kivimäki, Elovainio, and Vahtera, 2000; O'Donnell and MacIntosh, 2016; Vartia, 2001). Furthermore, those who experience workplace bullying report higher levels of burnout

\footnotetext{
* Corresponding author.

E-mail addresses: battell1@gsu.edu (B.K. Attell), kkummerowbrown1@gsu.edu (K. Kummerow Brown), ltreiber@kennesaw.edu (L.A. Treiber).
} 
and absenteeism coupled with lower levels of organizational commitment (Houshmand et al., 2012; Nielsen and Einarsen, 2012). These consequences of workplace bullying are exacerbated when employers, or those in charge, do not respond to reported acts of bullying. In a recent nationally representative sample of Americans, $44 \%$ of workers who reported an incident of bullying to a superior stated that the employer did nothing to address the situation (Namie, 2007). Therefore, understanding the complexity of the relationships between workplace bullying and adverse health outcomes is important in order to protect workers from poor physical and mental health and increase organizational commitment.

Despite widespread attention given to the prevalence, causes, and consequences of workplace bullying, few studies exist that examine how workplace bullying may differ depending on gender and race status. Therefore, the purpose of the current study is to contribute to this small body of literature by analyzing how the impact of workplace bullying on mental health outcomes differs among women and non-white individuals. Drawing from stress process theory, we also explore how social support from coworkers buffers the effect of workplace bullying on perceived job stressors and examine if women and nonwhite individuals benefit equally from this buffering effect. The findings of this analysis highlight the complexity of the connections between bullying in the workplace and adverse health outcomes.

\section{Background}

Despite several decades of research on workplace bullying, no universal definition of the phenomenon exists. However, there are several common features used by almost all researchers in their conceptualization of workplace bullying. At the most basic level, those who are bullied at work experience some sort of verbal or non-verbal negative behavior, which can be carried out by the perpetrator in overt or covert ways (Saunders et al., 2007). Additionally, workplace bullying results in physiological or psychological harm; those who are bullied have less power than their perpetrators; and those bullied label themselves as such (Saunders et al., 2007). Rayner and Hoel (1997) argue that there are several different types of workplace bullying, including threat to professional status, threat to personal standing, isolation, overwork, and destabilization at the place of employment. In addition to these definitions, one particularly useful conceptualization of workplace bullying includes several categories outlined by Escartín et al. (2011). They argue that workplace bullying can also include emotional abuse (humiliation or other insults), professional discrediting and denigration (belittling the individual's work and skills), and devaluation of the professional role (assigning workers tasks that are useless, meaningless, or do not match the skill level of the employee). Fox and Stallworth differentiate between general bullying and "racial/ethnic bullying," defined as actions that specifically target a person's race or ethnic group (2005:438).

Workplace bullying is a distinct and unique experience compared to the normal, everyday pressures that many individuals are exposed to in the workplace. Indeed, some central characteristics of work in general include negative or stressful interactions with coworkers or bosses, including minor jokes or teasing (Schnurr, 2009), or the pressure to meet imposed deadlines or efficiency standards from managers (Sparks et al., 2001). While these aspects of daily work life may be an anticipated part of joining the workforce, workplace bullying conceptually differs in several ways. Lutgen-Sandvik et al. (2007) argue that workplace bullying exists within a hierarchy of phenomena. The ordinary pressures of everyday work that characterize the culture of organizations exist at the superordinate level and affect all employees. However, workplace bullying is an interpersonal, subordinate phenomenon that does not widely affect all employees but is rather directed at targeted individuals through incivility, social ostracism, or verbal abuse and aggressiveness (Lutgen-Sandvik et al., 2007).

\subsection{Consequences of workplace bullying}

Many empirical studies find that workplace bullying is associated with severe adverse mental health outcomes for those bullied (Verkuil et al., 2015; Vega and Comer, 2005). For example, in a study of 1613 Norwegian employees, Einarsen and Nielsen (2014) found that individuals exposed to workplace bullying were 1.77 times more likely to exhibit psychological distress compared to those who were not exposed to workplace bullying. Similarly, Kivimäki et al. (2003) and Niedhammer et al. (2006) report that even when controlling for factors such as age, income, and educational level, workplace bullying remained a significant risk factor for depression. Both Einarsen and Nielsen (2014) and Quine (1999) found that anxiety levels were greater among those who were bullied at work compared to those who were not. Furthermore, the adverse mental health consequences of workplace bullying are traumatic and long standing. Drawing on a qualitative analysis of bullied victims from the public service industry, Hallberg and Strandmark found that when attempting to recover from bullying at work, victims felt as if they were "marked for life" (2006: 112). Several studies (Balducci et al., 2009; Matthiesen and Einarsen, 2004; Rodríguez-Muñoz et al., 2010; Tehrani, 2004) provide evidence that workplace bullying causes post-traumatic stress for those who were targeted victims. In a longitudinal study of workplace bullying and mental health, Finne et al. (2011) found that workplace bullying was a significant predictor of mental distress, even after two years had passed from the initial incident. Accordingly, hypothesis one of our study states that for all individuals, there is a positive relationship between workplace bullying and psychological distress.

\subsection{Gender and race differences in workplace bullying}

Compared to the substantial body of knowledge on workplace bullying and adverse mental health outcomes developed over the past 30 years, comparatively less attention has been paid to race and gender disparities in workplace bullying 
(Escartín et al., 2011). In 2001, Gardner and Johnson asserted that workplace bullying "transcends race, religion, or sex" (2001: 24), however, emerging work suggests otherwise. For example, in their analysis of 262 employees, Fox and Stallworth (2005) find that Hispanic and Latino employees report higher levels of general workplace bullying compared to their white coworkers. When including a specific measure of racial and ethnic bullying, Asians, African-Americans, and Hispanics report higher levels of workplace bullying compared to their white coworkers (Fox and Stallworth, 2005).

Furthermore, in her analysis of 1000 employees, Salin (2003b) finds that while 5 percent of male respondents report experiencing workplace bullying, close to 12 percent of women, or more than twice that of men, report being the victim of bullying in the workplace. Escartín et al. (2011) find that women assess the severity of isolation, emotional abuse, and professional discrediting in the workplace higher than men. Additionally, of people in managerial positions, women report more bullying than men, while in non-managerial positions men report more bullying than women (Salin and Hoel, 2013). This disparity indicates that gender is a critical factor in how workplace bullying manifests and how employees interpret that bullying.

In a 2014 study of workplace bullying in the United States, conducted by the Workplace Bullying Institute (WBI), Namie found that compared to other minorities and whites, a higher percentage of African Americans assigned blame for abusive workplace conduct to "society": with 30\% for African Americans, versus 4\% for Asians, 3\% for Hispanics, and $8 \%$ for whites (Namie, 2014). Although the 2014 WBI survey found that rates of being directly targeted for bullying for Asians (33.3\%), African Americans, (33.0\%) and Hispanics (32.5\%) were higher than for whites (24.1\%), these rates were very similar. To further assess the impact of those affected by bullying, Namie added measures of being a witness to bullying to being targeted personally. In this impact measure, Hispanics were affected at the highest rate (57\%) followed by African Americans (54\%), Asians (53\%), and Whites (44\%) (Namie, 2014).

Men and women experience bullying differently with divergent strategies for managing its effects. In a qualitative study of the academic workplace, Simpson and Cohen found that men reported bullying quickly, whereas women tended to endure it (Simpson and Cohen, 2004). Women are also more likely to avoid the situation, seek help, or do nothing about their bullying (Salin and Hoel, 2013). Men are more likely to respond to bullying by confrontation, retaliation, or with direct action (Salin, 2003b; Simpson and Cohen, 2004).

Gendered differences in self-identification may account for some of the disparities (Salin, 2003b) in the incidence rates. When presented with a definition of bullying, Salin (2003b) found that men were less likely than women to self-identify that they had been bullied. However, using a behavioral inventory, the differences between men and women's identification as having been bullied essentially disappeared. Salin (2003b) concluded that men might be less likely than women to openly acknowledge that they had been targets of bullying.

The most common approach to studying these differences to date has been the inclusion of race and gender as demographic control variables or covariates, minimalizing their focus in most studies. This method assumes that all members of the nominal categories-whether women or men, minorities or non-minorities- experience bullying in the same way. For example, Misawa (2015) described how the experiences of being bullied for gay men of color could differ from those of straight and/or white men. The focus on using race and gender merely as control variables has limited our knowledge about the complexity of workplace bullying and adverse mental health outcomes. While this approach has revealed, for example, that women may be bullied at work more often than men (Salin, 2003b) or that minority group members may experience instances of racial/ethnic bullying specifically targeting non-majority group identities (Fox and Stallworth, 2005), it does not shed light on the potential social processes that may explain these differences. There is a large body of evidence to support that workplace bullying has direct negative impacts on mental health (Verkuil et al., 2015; Vega and Comer, 2005), but we know less about indirect mechanisms that may influence the relationship between bullying and poor mental health, as well as how these indirect processes differ by gender and race. In this study, we address this gap in the literature by focusing on these indirect relationships and examining gender and racial differences specifically.

In addition to these methodological reasons, there are theoretical reasons why the mechanisms surrounding workplace bullying may differ depending on gender and race. Two theoretical perspectives, social dominance theory (Salin and Hoel, 2013) and critical management theory (Samnani, 2013), posit that in most organizations men and white individuals hold power in managerial positions that lay the foundation for women and minority race individuals in lower-power positions to be bullied. Because managers assign job-related tasks to those below them, they are the ones who have the opportunity to engage in bullying behaviors, like isolating or overworking employees or assigning them work that is useless, meaningless, or does not match the skill level of the employee. Additionally, Salin and Hoel (2013) argue that because men are more likely to be in managerial positions they may be more likely to dismiss the complaints of bullying from female employees.

Managers may also be protected from experiencing bullying because of their professional status as a manager. Indeed, organizational studies find that bullying at work most often occurs from a top-down perspective because non-managerial staff does not have the power or resources to bully their bosses (Yamada, 2008). Bullying tactics by managers can be concealed and legitimated in the guise of legitimate supervisory role of managerial control (Simpson and Cohen, 2004). Moreover, Salin (2003a) argues that even when formal power imbalances do not exist in organizations, workplace bullying may be more prevalent for women and other minorities because of the perceived power and status differences between minority and non-minority groups that exist in society at large. To that end, critical management theory holds that workplace bullying is a "reflection of the structural and power relationships in wider society" (Samnani, 2013: 32).

While social dominance theory and critical management theory provide insight as to why the prevalence of workplace bullying may broadly depend on gender and race, these theories are not particularly useful for examining the indirect 
pathways through which workplace bullying may adversely affect mental health outcomes. Both theories are focused on describing the organizational power differences or perceived power differences that exist at the intersection of managerial status, gender, and race. In this research, we shift our attention to stress process theory because it allows for better understanding of how individuals internalize workplace bullying and its emotional connections to health.

\section{Stress process theory}

Fig. 1 represents the theoretical model for the present study. Because the majority of empirical research explicitly focuses on the direct connections between workplace bullying and adverse outcomes, the analytical model relies on the framework of stress process theory in addition to previous research on workplace bullying. We draw specifically on the theoretical framework of stress process theory because of the large body of empirical evidence linking stressors to adverse mental health outcomes (Thoits, 2010). Indeed, many empirical studies directly link exposure to stress and poor mental health (for example, see Pearlin and Bierman, 2013; Turner, 2003; Turner and Avison, 2003; Wheaton, 1999).

For more than three decades, the stress process model (Pearlin et al., 1981) has served as one of the dominant sociological lenses for understanding health and illness. One of its central tenets is that illness is systematically distributed across society according to social status and one's exposure to stress (Aneshensel, 1992). Therefore, individuals belonging to marginalized groups, such as women and persons of color, are disadvantaged in their exposure to stress and may suffer more from the impact that stress has on mental health outcomes compared to individuals belonging to higher status groups (Pearlin and Bierman, 2013). Accordingly, hypothesis two states that the impact of workplace bullying on perceived job stressors and psychological distress is greater for women and persons of color.

Within stress process theory, stressors are conceptualized as "the broad array of problematic conditions and experiences that can challenge the adaptive capacities of people" (Pearlin, 2010: 208). Stressors can also be thought of as forces that are external to a person that challenge the capacity to function regularly, representing a main attribute of poor mental health (Wheaton et al., 2013). As such, stressors like workplace bullying place individuals at risk for adverse health outcomes, representing a direct connection between workplace bullying and psychological distress. An additional tenet of stress process theory is the notion of stress proliferation. Stress proliferation refers to the "new or 'secondary' stressors that emerge from 'primary' stressors, those to which people are initially exposed" (Pearlin and Bierman, 2013: 328). It is plausible, therefore, that workplace bullying may also increase the perception of other job-related stressors, such as feeling bothered or upset by work, or feeling that demands from work interfere with family life. Therefore, hypothesis three states that there is a positive and direct relationship between workplace bullying and perceived job stressors. The notion of stress proliferation is important because it calls attention to the multitude of pathways between stressors and adverse mental health outcomes. Because they are stressors in and of themselves, the process of stress proliferation is also attributable to adverse mental health outcomes (Pearlin and Bierman, 2013).

While stressors negatively impact mental health, individuals are equipped with coping resources that help to ameliorate the deleterious effects of stress on adverse outcomes. One such resource is social support, which refers to the emotional, physical, or tangible help that individuals provide to one another during day-to-day life or during times of crises or duress (Turner and Turner, 2013). For example, the men interviewed by O'Donnell and MacIntosh (2016) identified lack of social support as the main problem they faced when dealing with bullying, particularly if not given when requested. Men also reported feeling abandoned by those in a position to provide support (O'Donnell and MacIntosh, 2016). Although social support can be received from a variety of sources, such as friends or loved ones, most individuals draw on support from context specific groups when help is needed (for example, see Thoits, 2011 and Treiber and Davis, 2012). In the context of workplace bullying it is likely that individuals rely on the social support provided by coworkers to help buffer the consequences of bullying. As such, hypothesis four of this study states that coworker support will buffer the relationship between workplace bullying and perceived job stressors. However, for African American workers, there are differences in the quality and quantity of such relationships. African American workers may be less likely to receive the positive benefits of co-worker support and are often excluded from informal work networks, and thus, denied the potential benefits such networks provide (Bailey et al., 1996; Sloan et al., 2013).

\section{Data and methods}

The current study employs data from the 2010 Health and Retirement Study (HRS). The HRS is a long-running, nationally representative panel study of individuals aged 50 and older in the United States. The study design consists of a variety of topical modules presented to the entire sample during in-person data collection (March 2010 through November 2011) and special topical modules presented to random sub-samples of the larger group. The analysis in this study draws primarily from the psycho-social leave behind module, which is a paper survey respondents answered at home containing questions regarding (among others) workplace bullying, social support mechanisms, and psychological distress. The core 2010 data consists of 22,034 individuals. This investigation limited its analysis to those individuals who participated in the psycho-social leave behind module $(\mathrm{N}=8242)$ and those individuals working full or part-time $(\mathrm{N}=2898)$. One individual was dropped from the analysis due to missing data on all variables. Six hundred five individuals were dropped from the analysis due to missing data on exogenous variables. The final sample size for this analysis was 2292 individuals. 


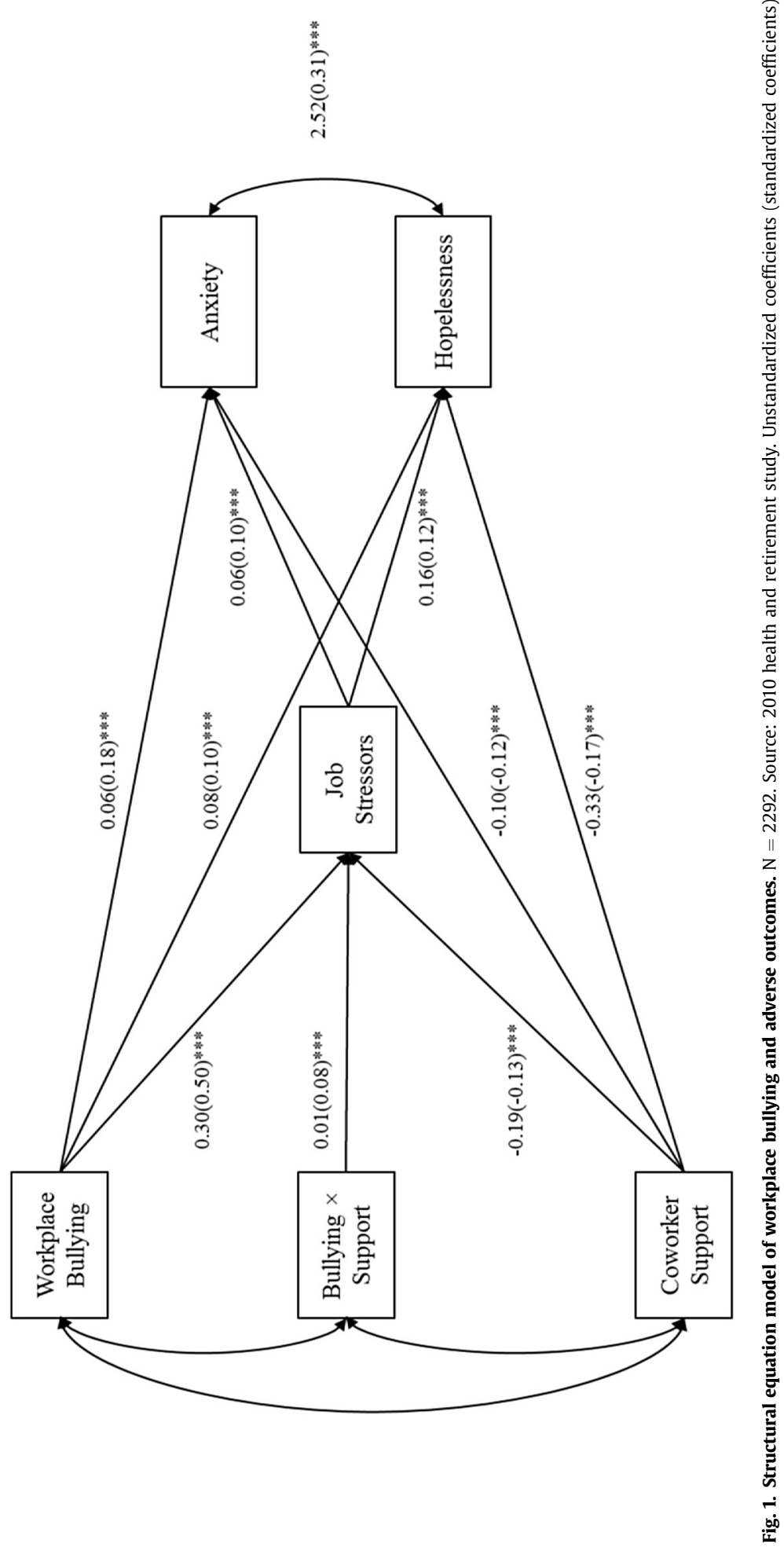




\subsection{Dependent (endogenous) variables}

This analysis consists of three dependent (endogenous) variables: perceived job stressors, anxiety, and hopelessness. Perceived job stressors was measured based on the demand/control model of stress (Karasek, 1979). When completing the survey, participants were asked to state how much they agree with the following six statements: "my job is physically demanding; I am under constant time pressure due to a heavy workload; I have very little freedom to decide how I do my work; considering the things I have to do at work, I have to work very fast; I often feel bothered or upset in my work; the demands of my job interfere with my personal life." Responses to each statement were coded at the ordinal level with 1 representing "strongly disagree" and 4 representing "strongly agree." The sum of all 6 statements was treated as a continuous measure in the model (Cronbach's $\alpha=0.72$ ). The measure ranged from 6 to 24 with higher values representing higher levels of perceived job stressors.

In this analysis, two mental health related variables serve as indicators of psychological distress: anxiety and hopelessness. Anxiety broadly refers to feelings of nervousness, uneasiness, and apprehension. Anxiety was measured using five items from the Beck Anxiety Inventory (Beck et al., 1988). When completing the survey, participants were asked to a list of statements and state how often they felt that way during the past seven days: "I had fear of the worst happening; I was nervous; I felt my hands trembling; I had a fear of dying; I felt faint." Responses to each statement were coded at the ordinal level with 0 representing "never" and 3 representing "most of the time." The sum of all five statements was treated as a continuous measure in the model (Cronbach's $\alpha=0.79$ ). The measure ranged from 0 to 15 with higher values representing higher levels of anxiety.

Hopelessness generally refers to feelings of despair where individuals feel that things cannot be improved. Hopelessness was measured using two items from Everson et al. (1997) and two items from Beck et al. (1974). When completing the survey, participants were asked to state how much they agree with the following four statements: "I feel it is impossible for me to reach the goals that I would like to strive for; the future seems hopeless to me and I can't believe that things are changing for the better; I don't expect to get what I really want; there's no use in really trying to get something I want because I probably won't get it." Responses to each statement were coded at the ordinal level with 1 representing "strongly disagree" and 6 representing "strongly agree." The sum of all four statements was treated as a continuous measure in the model (Cronbach's $\alpha=0.84$ ). The measure ranged from 4 to 24 with higher values representing higher levels of hopelessness.

\subsection{Independent (exogenous) variables}

This analysis consists of three independent (exogenous) variables: workplace bullying, social support from coworkers, and an interaction term. Workplace bullying is measured by the sum total of responses to six statements. Participants were asked to report how often they experienced the following behaviors at work in the past twelve months: "given the tasks at work that no one else wants to do; watched more closely than others; bothered by your supervisor or coworkers making slurs or jokes about women or racial or ethnic groups; have to work twice as hard as others at work; ignored or not taken seriously by your boss; been unfairly humiliated in front of others at work." Responses to each statement were coded at the ordinal level with 0 representing "never" and 5 representing "almost every day." The sum of all six statements was calculated and treated as a continuous measure in the model (Cronbach's $\alpha=0.81$ ). The measure ranged from 0 to 30 with higher values representing higher levels of workplace bullying. Our measure of workplace bullying closely fits the conceptual definitions outlined by previous researchers (see Escartín et al., 2011; Rayner and Hoel, 1997; Saunders et al., 2007).

Social support from coworkers is measured by the sum total of responses to four statements. When completing the survey, participants were asked to report how much they agree with the following statements: "the people I work with can be relied on when I need help; my coworkers listen to me when I need to talk about work-related problems; my coworkers help me with difficult tasks; my coworkers help me in crisis situations at work." Responses to each statement were coded at the ordinal level with 1 representing "strongly disagree" and 4 representing "strongly agree." The sum of all four statements was treated as a continuous measure in the model (Cronbach's $\alpha=0.91$ ). The measure ranged from 4 to 16 with higher values representing higher levels of coworker support.

The interaction term was created to examine if social support from coworkers buffered the relationship between workplace bullying and perceived job stressors by multiplying scores on the workplace bullying variable and the social support variable. Both the workplace bullying variable and the social support variable were mean centered prior to multiplication in order to prevent multicollinearity in the analysis and to preserve the assumption of independence of errors among variables (Jaccard and Turrisi, 2003).

\subsection{Analytic strategy}

Hypotheses were tested using structural equation modeling (SEM), a statistical technique that utilizes a full information maximum likelihood (FIML) algorithm to fit complex models to available data. Although significant advances have been made in regression-based approaches to model mediation and moderation, SEM is the preferred technique for testing the relationships hypothesized in Fig. 1 for several reasons. First, traditional regression-based approaches rely on listwise deletion for missing cases on all study variables, which reduces sample size and power. The FIML algorithm, on the other hand, imputes missing data for all endogenous variables in the model, and accordingly retains larger sample sizes and stronger sample 
power. Second, SEM software provides several indices that inform the researcher of model fit. Poor model fit indices indicate that the relationships hypothesized are unlikely to occur at the population level. Finally, SEM parameters include measurement errors in the calculation of path coefficients, which produce more accurate estimates of indirect effects when compared to traditional regression-based approaches (Little et al., 2007).

Data from the HRS were accessed, cleaned, and prepared for analysis using Stata SE version 13. The structural equation model was specified and estimated using MPlus version 7.3. The model tested in Fig. 1 is an over-identified model consisting of three observed independent variables (workplace bullying, social support from coworkers, and the interaction term multiplying the two), three observed dependent variables (perceived job stressors, anxiety, and hopelessness) and two degrees of freedom. Some of the variables were slightly skewed; however, because FIML can tolerate moderate violations of non-normality (Kline, 2011), we did not transform any of the variables. We assessed model fit using the guidelines outlined by Kline (2011) and Schreiber et al. (2006), where the following model fit indices are ideal: model chi-square greater than 0.05 with a non-significant p-value; comparative fit index (CFI) greater than 0.95; standardized root mean squared residual (SRMR) less than 0.08; and root mean square error of approximation (RMSEA) less than 0.06. It is important to note that with large sample sizes like the one utilized in the current study, a non-significant p-value for the model chi-square is rarely obtained (Kline, 2011).

In order to test for gender and race differences, we utilized a multiple-group approach via nested structural models. As Kline (2011) outlines: first, the model for all individuals in the sample is specified and estimated. If the model fits the data well, the same model is then estimated for separate groups, in this case a separate model for gender and a separate model for race. The separate models for each group are calculated and model fit indices are obtained. Next, the researcher constrains all paths in the model and compares model fit indices between the constrained and unconstrained models. If a statistically significant change in model chi-square is present, then the overall model is different for each group tested. We stratified the nested structural models using the provided gender and race variables from the HRS. Gender was stratified by "male" and "female" while race was stratified by "white/Caucasian," "black/African American," and "other race." In the remainder of this paper, we refer to "other race" individuals as "other minorities." The multiple group models were estimated using the GROUPING command in MPlus version 7.3 .

\section{Findings}

Sample demographics and descriptive statistics are reported in Table 1. There were more women $(\mathrm{N}=1288 ; 56 \%)$ than men $(\mathrm{N}=1004 ; 44 \%)$ in the sample. The majority of individuals in the sample were white $(\mathrm{N}=1739 ; 76 \%)$. Black individuals represented $16 \%(\mathrm{~N}=362)$ of the sample, while those reporting a race other than white or black were the smallest racial group present $(\mathrm{N}=191 ; 8 \%)$. For the entire sample, reported levels of workplace bullying $(\mathrm{M}=4.85$, S.D. $=5.71)$, perceived job stressors ( $\mathrm{M}=12.90$, S.D. $=3.36)$, anxiety $(\mathrm{M}=1.83$, S.D. $=1.96)$, and hopelessness $(\mathrm{M}=8.41, \mathrm{~S} . \mathrm{D} .=4.54)$ were relatively low. Coworker support, on the other hand, was high $(\mathrm{M}=12.72$, S.D. $=2.42)$.

As indicated by the descriptive statistics, distinct gender and race differences exist among the study variables. Compared to men, women reported higher levels of workplace bullying $(\mathrm{M}=4.92$, S.D. $=5.76)$, perceived job stressors $(\mathrm{M}=12.78$, S.D. $=3.50)$, and anxiety $(M=1.91$, S.D. $=2.06)$. Women reported lower levels of social support $(M=12.70$, S.D. $=2.46)$ and hopelessness ( $\mathrm{M}=8.27$; S.D. $=8.27)$. Compared to whites, black individuals reported higher levels of workplace bullying $(\mathrm{M}=6.62$, S.D. $=6.81)$, anxiety $(\mathrm{M}=2.17$, S.D. $=2.01)$, and hopelessness $(\mathrm{M}=8.53$, S.D. $=4.84)$. Compared to whites, other minority individuals reported higher levels of workplace bullying $(M=5.93$, S.D. $=6.38)$, perceived job stressors $(M=13.46$, S.D. $=3.57)$, anxiety $(M=2.15$, S.D. $=2.12)$, and hopelessness $(M=9.28$, S.D. $=5.03)$. Compared to whites, black individuals $(\mathrm{M}=12.19$, S.D. $=2.44)$ and other minority individuals $(\mathrm{M}=12.16, \mathrm{~S} . \mathrm{D} .=2.66)$ reported lower levels of coworker support.

Correlations between all study variables are presented in Table 2 . Workplace bullying was positively associated with perceived job stressors $(r=0.52, \mathrm{p}<0.001)$, anxiety $(r=0.28, \mathrm{p}<0.001)$, and hopelessness $(r=0.23, \mathrm{p}<0.001)$. Social support from coworkers was negatively associated with workplace bullying $(r=-0.40, \mathrm{p}<0.001)$, perceived job stressors $(r=-0.32, \mathrm{p}<0.001)$, anxiety $(r=-0.22, \mathrm{p}<0.001)$, and hopelessness $(r=-0.25, \mathrm{p}<0.001)$. Perceived job stressors was positively associated with anxiety $(r=0.24, \mathrm{p}<0.001)$ and hopelessness $(r=0.22, \mathrm{p}<0.001)$.

Table 1

Sample demographics and descriptive statistics.

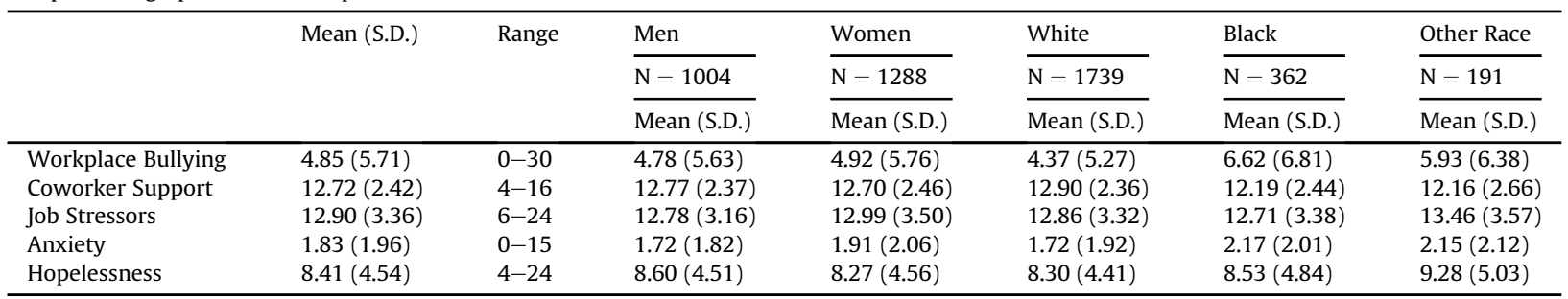

$\mathrm{N}=2292$. Source: 2010 Health and Retirement Study. Means appear in cells, standard deviations in parentheses. 
Table 2

Correlations between study variables.

\begin{tabular}{llll}
\hline & Workplace Bullying & Coworker Support & Job Stressors \\
\hline Workplace Bullying & - & & Anxiety \\
Coworker Support & $-0.40^{* * *}$ & - & - \\
Job Stressors & $0.52^{* * *}$ & $-0.32^{* * *}$ & $0.24^{* * *}$ \\
Anxiety & $0.28^{* * *}$ & $-0.22^{* * *}$ & $0.22^{* * *}$ \\
Hopelessness & $0.23^{* * *}$ & $-0.25^{* * *}$ & - \\
\hline
\end{tabular}

$\mathrm{N}=2292$. Source: 2010 Health and Retirement Study. ${ }^{* * *} \mathrm{p} \leq 0.001$.

The parameter estimates for the structural equation model using the entire sample are presented in Fig. 1. The a priori model drawing on stress process theory fit the data well: $\mathrm{M} \chi^{2}(2)=9.82, \mathrm{p}<0.05$, RMSEA $=0.04, \mathrm{CFI}=0.99, \mathrm{SRMR}=0.01$, with no post hoc modifications necessary to increase model fit. There were significant positive relationships between workplace bullying and perceived job stressors $(b=0.30, p<0.001)$, anxiety $(b=0.06, p<0.001)$, and hopelessness $(b=0.08, p<0.001)$. There were also significant negative relationships between coworker support and perceived job stressors $(b=-0.19, p<0.001)$, anxiety $(b=-0.10, p<0.001)$, and hopelessness $(b=-0.33, p<0.001)$. The interaction term modeling the buffering effect of coworker support and workplace bullying on perceived job stressors was significant $(b=0.01$, $\mathrm{p}<0.001)$. Accordingly, coworker support moderated the relationship between workplace bullying and perceived job stressors. The model explains about a third of the variation in job stressors $\left(\mathrm{R}^{2}=0.29\right)$. Though all paths were significant, the model did not explain much of the variation in anxiety $\left(R^{2}=0.10\right)$ or hopelessness $\left(R^{2}=0.09\right)$.

The parameter estimates for the multiple-group structural equation model are displayed in Table 3. Each dependent variable is listed as a row heading, with independent variables indented below. The unconstrained multiple group model for gender fit the data well $\mathrm{M} \chi^{2}(4)=15.12, \mathrm{p}<0.01$, RMSEA $=0.05, \mathrm{CFI}=0.99$, SRMR $=0.01$, with no post hoc modifications necessary. The change in model chi-square between the unconstrained and constrained gender model was significant $\left(\Delta \mathrm{M} \chi^{2}\right.$ $(19)=853.246, \mathrm{p}<0.001)$. Therefore, gender moderated all structural paths in the model. Comparing the structural regression coefficients for the model highlights the gender disparities. The impact of workplace bullying on perceived job stressors is higher for women $(b=0.31, p<0.001)$ compared to men $(b=0.28, p<0.001)$. Furthermore, the impact of coworker support on perceived job stressors is greater for men $(b=-0.19, p<0.001)$, and women benefit less from the protective buffering mechanism of social support on perceived job stressors ( $b=0.01, p<0.05$ ). Compared to women, men are more heavily impacted by the effects of workplace bullying on anxiety $(b=0.08, p<0.001)$. However, women benefit more from the effect of social support on anxiety $(b=-0.10, p<0.001)$ and hopelessness $(b=-0.34, p<0.001)$. Perceived job stressors impact anxiety at a higher degree for women $(b=0.07, p<0.001)$ and hopelessness at a higher degree for men $(\mathrm{b}=0.23, \mathrm{p}<0.001)$.

Race differences in the multiple-group structural equation model are also presented in Table 3. The unconstrained multiple group model for race fit the data well $\mathrm{M} \chi^{2}(6)=23.80, \mathrm{p}<0.001$, RMSEA $=0.06$, CFI $=0.99$, SRMR $=0.02$, with no post hoc modifications necessary. The change in model chi-square between the unconstrained and constrained race model was significant $\left(\Delta \mathrm{M} \chi^{2}(24)=881.681, \mathrm{p}<0.001\right)$. Therefore, race moderated all structural paths in the model. The impact of workplace bullying on perceived job stressors was greatest for other minority individuals $(b=0.32, p<0.001)$ and lowest for

Table 3

Results of the structural equation model with group differences.

\begin{tabular}{|c|c|c|c|c|c|c|}
\hline Dependent Variable & Entire Sample & Men & Women & White & Black & Other Race \\
\hline \multirow[t]{2}{*}{ Independent Variable } & $\mathrm{N}=2292$ & $\mathrm{~N}=1004$ & $\mathrm{~N}=1288$ & $\mathrm{~N}=1739$ & $\mathrm{~N}=362$ & $\mathrm{~N}=191$ \\
\hline & $\mathbf{b}(\beta)$ & $\mathrm{b}(\beta)$ & $\mathrm{b}(\beta)$ & $\mathrm{b}(\beta)$ & $\mathbf{b}(\beta)$ & $\mathrm{b}(\beta)$ \\
\hline \multicolumn{7}{|l|}{ Perceived Job Stressors } \\
\hline Workplace Bullying & $0.30(0.50)^{* * *}$ & $0.28(0.02)^{* * *}$ & $0.31(0.51)^{* * *}$ & $0.31(0.50)^{* * *}$ & $0.25(0.50)^{* * *}$ & $0.32(0.57)^{* * *}$ \\
\hline Coworker Support & $-0.19(-0.13)^{* * *}$ & $-0.19(0.04)^{* * *}$ & $-0.18(-0.13)^{* * *}$ & $-0.20(-0.14)^{* * *}$ & $-0.11(-0.08)$ & $-0.25(-0.18)^{*}$ \\
\hline Bullying x Support & $0.01(0.08)^{* * *}$ & $0.02(0.00)^{*}$ & $0.01(0.07)^{*}$ & $0.02(0.08)^{* * *}$ & $-0.00(-0.01)$ & $0.02(0.14)$ \\
\hline \multicolumn{7}{|l|}{ Anxiety } \\
\hline Workplace Bullying & $0.06(0.18)^{* * *}$ & $0.08(0.01)^{* * *}$ & $0.05(0.14)^{* * *}$ & $0.07(0.20)^{* * *}$ & $0.03(0.09)$ & $0.05(0.17)$ \\
\hline Coworker Support & $-0.10(-0.12)^{* * *}$ & $-0.09(0.02)^{* * *}$ & $-0.10(-0.11)^{* * *}$ & $-0.12(-0.15)^{* * *}$ & $0.01(0.02)$ & $-0.03(-0.04)$ \\
\hline Perceived Job Stressors & $0.06(0.10)^{* * *}$ & $0.05(0.02)^{* * *}$ & $0.07(0.11)^{* * *}$ & $0.06(0.10)^{* * *}$ & $0.08(0.13)$ & $0.05(0.08)$ \\
\hline \multicolumn{7}{|l|}{ Hopelessness } \\
\hline Workplace Bullying & $0.08(0.10)^{* * *}$ & $0.12(0.03)^{* * *}$ & $0.04(0.06)$ & $0.10(0.12)^{* * *}$ & $0.06(0.08)$ & $0.03(0.04)$ \\
\hline Coworker Support & $-0.33(-0.17)^{* * *}$ & $-0.30(0.06)^{* * *}$ & $-0.34(-0.18)^{* * *}$ & $-0.40(-0.21)^{* * *}$ & $-0.08(-0.04)$ & $-0.13(-0.07)$ \\
\hline Perceived Job Stressors & $0.16(0.12)^{* * *}$ & $0.23(0.05)^{* * *}$ & $0.11(0.09)^{*}$ & $0.16(0.12)^{* * *}$ & $0.07(0.05)$ & $0.19(0.13)$ \\
\hline \multicolumn{7}{|l|}{$\mathrm{R}^{2}$} \\
\hline Perceived Job Stressors & 0.29 & 0.28 & 0.30 & 0.30 & 0.29 & 0.35 \\
\hline Anxiety & 0.10 & 0.14 & 0.08 & 0.13 & 0.04 & 0.06 \\
\hline Hopelessness & 0.09 & 0.14 & 0.07 & 0.13 & 0.02 & 0.04 \\
\hline
\end{tabular}

$\mathrm{N}=2292$. Source: 2010 Health and Retirement Study. Unstandardized coefficients appear in cells, standardized coefficients appear in parentheses. ${ }^{*} \mathrm{p}=0.05$, ${ }^{* *} \mathrm{p}=0.01,{ }^{* * *} \mathrm{p}=0.001$. 
black individuals $(\mathrm{b}=0.25, \mathrm{p}<0.001)$. However, white individuals were the only group to benefit from the protective buffering mechanism of coworker support on perceived job stressors $(b=0.02, p<0.001)$.

\section{Discussion}

Work occupies a central role in the lives of Americans. While the workplace can be a site of productivity and a source of happiness, an overwhelming body of literature documents that for those bullied in the workplace, work becomes a source of stress and consequently severe adverse physical and mental health outcomes. The goal of the current study was to contribute to a limited body of literature on gender and race differences that exist in the previously established relationships between workplace bullying and adverse mental health outcomes. Drawing from stress process theory, we also explored how social support from coworkers buffers the effect of workplace bullying on perceived job stressors and examined if women and nonwhite individuals benefited equally from this buffering effect.

The results of our analysis supported hypothesis one, which proposed a positive relationship between workplace bullying and psychological distress. In testing the relationship between workplace bullying and psychological distress, we specifically examined the impact that bullying has on anxiety and hopelessness. We found positive associations in the relationships between workplace bullying and its impact on anxiety and hopelessness, although the strength of the relationships for both outcomes was relatively small compared to the effect of workplace bullying on perceived job stressors. Nonetheless, our findings for this hypothesis align with previous research that documents the adverse mental health outcomes associated with experiencing bullying in the workplace (Kivimäki et al., 2003; Niedhammer et al., 2006; Quine, 1999; Sa and Fleming, 2008; Vega and Comer, 2005).

To date, the role of minority disparities in the relationships that exist between workplace bullying and adverse mental health outcomes has been understudied. Therefore, perhaps the most important findings of our analysis are the results of our tests for hypothesis two, which stated that the impact of workplace bullying on perceived job stressors and psychological distress is greater for women and persons of color. Consistent with previous research (Salin, 2003b), women in our sample reported higher levels of workplace bullying compared to men. However, the full results of our analysis are more nuanced than originally anticipated. In regards to the direct effect of bullying on perceived job stressors, we found that bullying had a greater impact on women's perceived job stressors than on men's perceived job stressors.

Furthermore, though women were affected more by the impact of workplace bullying on perceived job stressors, men benefited more from the protective buffering mechanism of social support from coworkers. This finding seems to run counter to previous research which suggests that women are more likely to deal with stressors by seeking out emotional support from others (Folkman et al., 1987; Parkes, 1990) while men tend to use methods that rely on self-control (Parkes, 1990). However, social support from coworkers provided a stronger buffer against anxiety and hopelessness for women so it may be that social support does not protect against stress directly, but helps women cope with that stress better than men. It is also possible that because women experienced more workplace bullying and were more affected by that bullying they were not getting enough coworker support to protect against perceived job stressors. However, recent qualitative research on men who were targets of bullying found that they placed a high value on the role of social support (O'Donnell and MacIntosh, 2016).

Compared to women, men were more heavily affected by the impact of workplace bullying on both anxiety and hopelessness. This difference may be due to the perception that working and being successful in the workplace have greater importance for men's mental health than for women's mental health. Unemployment is more strongly associated with poor mental health in men than it is in women (Artazcoz et al., 2004). Additionally, men are more likely to believe that providing economic support is a key part of their family role and employment has a positive effect on men's self-perceptions as fathers and husbands (Simon, 1995). Being bullied at work could be perceived as a threat to the ability to fulfill the role of financial provider which could lead to feelings of hopelessness. However, further research should be conducted to explore this connection.

Similar to Fox and Stallworth (2005), we found that the mean levels of workplace bullying for blacks and respondents identified as "other race" were higher than their white coworkers. However, of all three races present in our sample, the impact of workplace bullying on perceived job stressors was greatest for respondents identified as "other race" and the lowest for black respondents. This finding underscores the importance of understanding that all members of minority groups do not experience bullying in the same way. However, the white respondents in our sample were the only group to benefit from the protective buffering mechanism of social support from coworkers. Previous research indicates that racism and racial discrimination at the workplace can add to stress on the job. For example, Tomaskovic-Devey found that black workers receive closer scrutiny on the job in part because of the types of jobs they hold, but also "because they are black" (TomaskovicDevey, 1993:148). In addition to close monitoring, expressing one's feelings and negative emotions on the job can have different outcomes for white and black workers. For example, black workers may feel that they would be punished for expressing anger or job dissatisfaction in the same manner as their white co-workers (Wingfield, 2010). Thus, while white workers may be able to discuss negative work events with co-workers, black workers may not be comfortable "letting off steam" in this way, leading to the increased stress of holding emotions inside.

Previous research on the associations between workplace bullying and stress are somewhat contradictory, with evidence suggesting a bi-directional relationship between bullying and stress (Hoel et al., 2002). In our analysis, we drew on the concept of stress proliferation (Pearlin and Bierman, 2013) to test hypothesis three, which proposed a positive relationship between workplace bullying and perceived job stressors. Consistent with previous literature (Agervold and Mikkelsen, 2004; 
Hauge et al., 2010), the results of our analysis indicate that workplace bullying is positively associated with perceived job stressors. Of all paths estimated in our model, the relationship between workplace bullying and perceived job stressors, was in fact, the strongest. In light of stress process theory, this finding supports the notion that workplace bullying exacerbates other stressors experienced at work.

Several previous studies (Cooper-Thomas et al., 2013; Nielsen et al., 2008; Schat and Kelloway, 2003) examine potential buffering mechanisms that help ameliorate the deleterious effects of workplace bullying. Whereas previous researchers focused on buffers such as a strong sense of coherence, we shifted our attention to the role of social support from coworkers. Because social support is context specific (Thoits, 2011), we believed that those who experienced bullying at work would turn to their coworkers for help and guidance. Accordingly, hypothesis four stated that coworker support buffers the relationship between workplace bullying and perceived job stressors. The results of our analysis indicate that while social support from coworkers does buffer the relationship between workplace bullying and perceived job stressors, the effect is relatively small.

While the findings of our analysis are important in their own light, there are several limitations to our study that must be acknowledged. First, our analysis is of cross-sectional data. Longitudinal data allow for stronger causal claims to be made in the types of relationships that we tested in our model. Accordingly, future research should draw on a repeated measures design to test the longitudinal plausibility of the cross-sectional associations we found to be significant. Second, while the results of our analysis reveal minority disparities in the social processes surrounding workplace bullying and adverse mental health outcomes, future research should aim to understand if conceptualizations of workplace bullying are distinctly unique for women or persons of color, who may be experiencing gender based harassment or racial discrimination in addition to bullying. Also, as we do not have measures of sexualities in the data, some instances of bullying based on sexual orientation may be hidden or occur in concert with gender, race, or ethnic categories. Finally, the sample for this study was based on employed older adults who have multiple years of exposure to both the benefits and hazards of work. Further research could compare younger workers with older ones to tease out some of the effects of job experience, work longevity, age, and generational affiliation. Our understanding if the stress effects of bullying could also be improved by considering intersectional statuses of workers.

\section{Conclusion}

Bullying in the workplace has brought about considerable policy changes in many countries. For example, in Sweden, Britain, France, Australia, Ireland, Australia, and Canada, legislators have enacted federal laws making workplace bullying illegal (Namie, 2013; Sheehan et al., 1999). Even with overwhelming public opinion for legal reform, in the United States such federal legislation does not exist (Yamada, 2010). However, as of 2013 roughly half of all states have adopted the Healthy Workplace Bill, making many aspects of workplace bullying illegal (Namie, 2013).

Given the results of our study of workplace bullying in a nationally representative sample of adult Americans over age 50 which highlight the deleterious effects of workplace bullying, considering such legislation in the United States seems more essential. Our findings add to a well-established body of literature documenting the ways that workplace bullying negatively impacts the mental health of employees. In particular, we provide evidence that workplace bullying involves a process of stress proliferation, where workplace bullying is a stressor that exacerbates other stressors that individuals may experience at work. We also provide evidence that social support from coworkers helps to buffer the stress proliferation process. Furthermore, we argue that workplace bullying does not transcend race or sex. As indicated by our findings, women and black individuals in our sample were more heavily impacted by the effects of workplace bullying, and protected less from the buffering mechanism of social support from coworkers. Taken together, these findings highlight the importance of studying gender and race differences in the processes surrounding workplace bullying. As sociologists continue to better understand the adverse mental health outcomes associated with workplace bullying, future research should continue to account for how these processes may be different for women or persons of color.

We must also question the working environments and managerial practices that allow bullying to occur. Although employment policies that govern behavior are ostensibly neutral, mounting evidence suggests that such rules are implicitly racialized (Wingfield, 2010). Another consideration for further investigation is the role of tokenism (Kanter, 1977) in the creation of discriminatory environments for highly visible minority workers. For example, would being the only women or non-white member of a workgroup subject one to increased victimization? Future research should examine the racial and gender composition of the workplace and how its variations influence social support, stress, and workplace bullying.

\section{Funding}

The HRS (Health and Retirement Study) is sponsored by the National Institute on Aging (grant number NIA U01AG009740) and is conducted by the University of Michigan.

\section{Acknowledgements}

The authors would like to thank Betty S. Lai and Eric R. Wright for their thoughtful feedback on previous drafts of this paper.

Please cite this article in press as: Attell, B.K., et al., Workplace bullying, perceived job stressors, and psychological distress: Gender and race differences in the stress process, Social Science Research (2017), http://dx.doi.org/10.1016/ j.ssresearch.2017.02.001 


\section{References}

Agervold, Mogens, Mikkelsen, Eva Gemzoe, 2004. Relationships between bullying, psychosocial work environment, and individual stress reactions. Work Stress 18 (4), 336-351.

Aneshensel, Carol, 1992. Social stress: theory and research. Annu. Rev. Sociol. 18, 15-38.

Artazcoz, Lucía, Benach, Joan, Borrell, Carme, Cortès, Immaculada, 2004. Unemployment and mental health: understanding the interactions among gender, family roles, and social class. Am. J. Public Health 94 (1), 82-88.

Bailey, Darlyne, Wolfe, Donald, Wolfe, Christopher R., 1996. The contextual impact of social support across race and gender: implications for african american women in the workplace. J. Black Stud. 26 (3), 287-307.

Balducci, Cristian, Alfano, Vincenzo, Fraccaroli, Franco, 2009. Relationships between mobbing at work and MMPI-2 personality profile, posttraumatic stress symptoms, and suicidal ideation and behavior. Violence Vict. 24 (1), 52-67.

Beck, Aaron T., Weissman, Arlene, Lester, David, Trexler, Larry, 1974. The measurement of pessimism: the hopelessness scale. J. Consult. Clin. Psychol. 42 (6), 861-865. http://dx.doi.org/10.1037/h0037562.

Beck, Aaron T., Epstein, Norman, Brown, Gary, Steer, Robert A., 1988. An inventory for measuring clinical anxiety: psychometric properties. J. Consult. Clin. Psychol. 56 (6), 893-897. http://dx.doi.org/10.1037/0022-006X.56.6.893.

Cooper-Thomas, Helena, Gardner, Dianne, O'Driscoll, Michael, Catley, Bevan, Bentley, Tim, Trenberth, Linda, 2013. Neutralizing workplace bullying: the buffering effects of contextual factors. J. Manag. Psychol. 28 (4), 384-407.

Einarsen, Stale, Hoel, Helge, Cooper, Cary L., 2004. Bullying and Emotional Abuse in the Workplace: International Perspectives in Research and Practice. Taylor \& Francis, New York.

Einarsen, Stale, Hoel, Helge, Zapf, Dieter, Cooper, Cary L., 2011. Bullying and Harassment in the Workplace: Developments in Theory, Research, and Practice. Talor \& Francis, Boca Raton, FL.

Einarsen, Stale, Nielsen, Morten B., 2014. Workplace bullying as an antecedent of mental health problems: a five-year prospective and representative study. Int. Arch. Occup. Environ. Health 1-12. http://dx.doi.org/10.1007/s00420-014-0944-7.

Escartín, Jordi, Salin, Denise, Rodriguez-Carballeira, Alvaro, 2011. Conceptualization of workplace bullying: gendered rather than gender neutral? J. Pers. Psychol. 10 (4), 157-165.

Escartín, Jordi, Ullrich, Johannes, Zapf, Dieter, Schlüter, Elmar, Dick, Rolf van, 2012. Individual- and group-level effects of social identification on workplace bullying. Eur. J. Work Organ. Psychol. 22 (2), 182-193.

Everson, Susan A., Kaplan, George A., Goldberg, Debbie E., Salonen, Riitta, Salonen, Jukka T., 1997. Hopelessness and 4-year progression of carotid atherosclerosis: the kuopio ischemic heart disease risk factor study. Arterioscler. Thromb. Vasc. Biol. 17 (8), 1490-1495. http://dx.doi.org/10.1161/01.atv. 17.8.1490.

Finne, Live Bakke, Knardahl, Stein, Lau, Bjørn, 2011. Workplace bullying and mental distress-a prospective study of norwegian employees. Scand. J. Work Environ. Health 37 (4), 276-287.

Folkman, Susan, Lazarus, Richard S., Pimley, Scott, Novacek, Jill, 1987. Age differences in stress and coping processes. Psychol. Aging 2 (2), 171-184.

Fox, Suzy, Stallworth, Lamont E., 2005. Racial/ethnic bullying: exploring the links between bullying and racism in the U.S. Workplace. J. Vocat. Behav. 66 (3), 438-456.

Gardner, Susan, Johnson, Pamela R., 2001. The leaner, meaner workplace: strategies for handling bullies at work. Employ. Relat. Today 28 (2), 23-36. http:// dx.doi.org/10.1002/ert.1012.

Hallberg, Lillemor RM., Strandmark, Margaretha K., 2006. Health consequences of workplace bullying: experiences from the perspective of employees in the public service sector. Int. J. Qual. Stud. Health Well-Being 1 (2), 109-119.

Hauge, Lars Johan, Skogstad, Anders, Einarsen, Ståle, 2010a. The relative impact of workplace bullying as a social stressor at work. Scand. J. Psychol. 51 (5), 426-433.

Hoel, Helge, Zapf, Dieter, Cooper, Cary L., 2002. Workplace bullying and stress. Res. Occup. Stress Well-Being 2, $293-333$.

Houshmand, Marjan, O'Reilly, Jane, Robinson, Sandra, Wolff, Angela, 2012. Escaping bullying: the simultaneous impact of individual and unit-level bullying on turnover intentions. Hum. Relat. 65 (7), 901-918.

Jaccard, James, Turrisi, Robert, 2003. Interaction Effects in Multiple Regression. Sage, Thousand Oaks, CA.

Kanter, Rosabeth Moss, 1977. Men and Women of the Corporation. Basic Books, New York.

Karasek Jr., Robert A., 1979. Job demands, job decision latitude, and mental strain: implications for job redesign. Adm. Sci. Q. 24 (2), 285-308. http://dx.doi. org/10.2307/2392498.

Kivimäki, M., Elovainio, M., Vahtera, J., 2000. Workplace bullying and sickness absence in hospital staff. Occup. Environ. Med. 57 (10), 656-660.

Kivimäki, M., Virtanen, M., Vartia, M., Elovainio, M., Vahtera, J., Keltikangas-Järvinen, L., 2003. Workplace bullying and the risk of cardiovascular disease and depression. Occup. Environ. Med. 60 (10), 779-783.

Kline, Rex B., 2011. Principles and Practice of Structural Equation Modeling. Guilford Press, New York, NY.

Little, Todd D., Card, Noel A., Bovaird, James A., Preacher, Kristopher J., Crandall, Christian S., 2007. Structural equation modeling of mediation and moderation with contextual factors. In: Little, T.D., Bovaird, J.A., Card, N.A. (Eds.), Modeling Contextual Effects in Longitudinal Studies. Lawrence Erlbaum Associates, Mahwah, NJ, pp. 207-230.

Lutgen-Sandvik, Pamela, Tracy, Sarah J., Alberts, Jess K., 2007. Burned by bullying in the american workplace: prevalence, perception, degree and impact. J. Manag. Stud. 44 (6), 837-862. http://dx.doi.org/10.1111/j.1467-6486.2007.00715.x.

Matthiesen, Stig Berge, Einarsen, Ståle, 2004. Psychiatric distress and symptoms of PTSD among victims of bullying at work. Br. J. Guid. Couns. 32 (3), 335-356.

Misawa, Mitsunori, 2015. Cuts and bruises caused by arrows, sticks, and stones in academia: theorizing three types of racist and homophobic bullying in adult and higher education. Adult Learn. 26 (1), 6-13. http://dx.doi.org/10.1177/1045159514558413.

Namie, G., September, 2007. U.S. Workplace Bullying Survey. The Workplace Bullying Institute.

Namie, Gary, 2010. The WBI U.S. Workplace Bullying Survey. The Workplace Bullying Institute.

Namie, Gary, 2013. The International Legislative Movement available online at: http://www.healthyworkplacebill.org/international.php.

Namie, Gary, 2014. Workplace Bullying: Race, Ideology, and the U.S. Bullying Experience: 2014 WBI Workplace Bullying Survey. Workplace Bullying Institute. Retrieved December 18, 2016. http://www.workplacebullying.org/2014-race/.

Niedhammer, Isabelle, David, Simone, Degioanni, Stephanie, 2006. Association between workplace bullying and depressive symptoms in the french working population. J. Psychosom. Res. 61 (2), 251-259.

Nielsen, Morten Birkeland, Einarsen, Stale, 2012. Outcomes of exposure to workplace bullying: a meta-analytic review. Work Stress 26 (4), 309-332.

Nielsen, Morten Birkeland, Matthiesen, Stig Berge, Einarsen, Ståle, 2008. Sense of coherence as a protective mechanism among targets of workplace bullying. J. Occup. Health Psychol. 13 (2), 128.

O'Donnell, Sue M., MacIntosh, Judith A., 2016. Gender and workplace bullying: men's experiences of surviving bullying at work. Qual. Health Res. 26 (3), 351-366. http://dx.doi.org/10.1177/1049732314566321.

Parkes, Katharine R., 1990. Coping, negative affectivity, and the work environment: additive and interactive predictors of mental health. J. Appl. Psychol. 75 (4), 399.

Pearlin, Leonard, 2010. The life course and the stress process: some conceptual comparisons. J. Gerontol. Ser. B Psychol. Sci. Soc. Sci. 65 (2), 207-215.

Pearlin, Leonard L., Bierman, Alex, 2013. Current issues and future directions in research into the stress process. In: Aneshensel, C.S., Phelan, J.C., Bierman, A. (Eds.), Handbook of the Sociology of Mental Health. Springer, New York, NY, pp. 325-340.

Pearlin, Leonard, Menaghan, Elizabeth, Lieberman, Morton, Mullan, Joseph, 1981. The stress process. J. Health Soc. Behav. 22 (4), $337-356$. 
Quine, Lyn, 1999. Workplace bullying in NHS community trust: staff questionnaire survey. Br. Med. J. 318 (7178), $228-232$.

Rayner, Charlotte, 1997. The incidence of workplace bullying. J. Community Appl. Soc. Psychol. 7 (3), 199-208.

Rayner, Charlotte, Hoel, Helge, 1997. A summary review of literature relating to workplace bullying. J. Community Appl. Soc. Psychol. 7 (3), 181-191.

Rayner, Charlotte, Hoel, Helge, Cooper, Cary L., 2002. Workplace Bullying: what We Know, Who Is to Blame, and what Can We Do? Taylor \& Francis, London.

Rodríguez-Muñoz, Alfredo, Moreno-Jiménez, Bernardo, Isabel Sanz Vergel, Ana, Hernández, Eva Garrosa, 2010. Post-traumatic symptoms among victims of workplace bullying: exploring gender differences and shattered assumptions. J. Appl. Soc. Psychol. 40 (10), 2616-2635.

Sa, Luis, Fleming, Manuela, 2008. Bullying, burnout, and mental health amongst portuguese nurses. Issues Ment. Health Nurs. 29 (4), $411-426$.

Salin, Denise, 2003a. Ways of explaining workplace bullying: a review of enabling, motivating, and precipitating structures and processes in the work environment. Hum. Relat. 56 (10), 1213-1232.

Salin, Denise, 2003b. The significance of gender in the prevalence, forms, and perceptions of workplace bullying. Nord. Organ. 5 (3), 30-50.

Salin, Denise, Hoel, Helge, 2013. Workplace bullying as a gendered phenomenon. J. Manag. Psychol. 28 (3), $235-251$.

Samnani, Al-Karim, 2013. Embracing new directions in workplace bullying research: a pardigmatic approach. J. Manag. Inq. 22 (1), $26-36$.

Saunders, Paula, Huynh, Amy, Goodman-Delahunty, Jane, 2007. Defining workplace bullying: behaviour, professional, and lay definitions of workplace bullying. Int. J. Law Psychiatry 30 (4), 340-354.

Schat, Aaron C.H., Kelloway, E. Kevin, 2003. Reducing the adverse consequences of workplace aggression and violence: the buffering effects of organizational support. J. Occup. Health Psychol. 8 (2), 110-122.

Schnurr, Stephanie, 2009. Constructing leader identities through teasing at work. J. Pragmat. 41 (6), 1125-1138.

Schreiber, James B., Nora, Amaury, Stage, Frances K., Barlow, Elizabeth A., King, Jamie, 2006. Reporting structural equation modeling and confirmatory factor analysis results: a review. J. Educ. Res. 99 (6), 323-338.

Sheehan, Michael, Barker, Michelle, Rayner, Charlotte, 1999. Applying strategies for dealing with workplace bullying. Int. J. Manpow. 20 (1/2), $50-57$.

Simon, Robin W., 1995. Gender, multiple roles, role meaning, and mental health. J. Health Soc. Behav. 36 (2), $182-194$.

Simpson, Ruth, Cohen, Claire, 2004. Dangerous work: the gendered nature of bullying in the context of higher education. Gend. Work Organ. 11 (2), 163-186. http://dx.doi.org/10.1111/j.1468-0432.2004.00227.x.

Sloan, Melissa M., Ranae, J. Evenson Newhouse, Thompson, Ashley B., 2013. Counting on coworkers: race, social support, and emotional experiences on the job. Soc. Psychol. Q. 76 (4), 343-372.

Sparks, Kate, Faragher, Brian, Cooper, Cary L., 2001. Well-being and occupational health in the 21st century workplace. J. Occup. Organ. Psychol. 74 (4), 489-509. http://dx.doi.org/10.1348/096317901167497.

Tehrani, Noreen, 2004. Bullying: a source of chronic post traumatic stress? Br. J. Guid. Couns. 32 (3), 357-366.

Thoits, Peggy A., 2010. Stress and health: major findings and policy implications. J. Health Soc. Behav. 51 (Suppl. ment), S41-S53.

Thoits, Peggy A., 2011. Mechanisms linking social ties and support to physical and mental health. J. Health Soc. Behav. 52 (2), 145-161.

Tomaskovic-Devey, Donald, 1993. Gender and Racial Inequality at Work. Industrial Labor Relations Press, Ithaca, NY.

Treiber, L.A., Davis, S.N., 2012. The role of 'workplace family' support on worker health, exhaustion and pain. Community Work Fam. 15 (1), 1-27.

Turner, R. Jay, 2003. The pursuit of socially modifiable contingencies in mental health. J. Health Soc. Behav. 44 (1), 1-17.

Turner, R. Jay, Avison, William R., 2003. Status variations in stress exposure: implications for the interpretation of research on race, socioeconomic status, and gender. J. Health Soc. Behav. 44 (4), 488-505.

Turner, J. Blake, Turner, R. Jay, 2013. Social relations, social integration, and social support. In: Aneshensel, C.S., Phelan, J.C., Bierman, A. (Eds.), Handbook of the Sociology of Mental Health. Springer, New York, NY, pp. 341-356.

Vartia, Maarit A.L., 2001. Consequences of workplace bullying with respect to the well-being of its targets and the observers of bullying. Scand. J. Work Environ. Health 27 (1), 63-69.

Vega, Gina, Comer, Debra, 2005. Sticks and stones may break your bones, but words can break your spirit: bullying in the workplace. J. Bus. Ethics 58 (1-3), $101-109$.

Verkuil, Bart, Atasayi, Serpil, Molendijk, Marc L., 2015. Workplace bullying and mental health: a meta-analysis on cross-sectional and longitudinal data. PLoS One $10(8), 1-16$.

Wheaton, Blair, 1999. The nature of stressors. In: Horwitz, A.V., Scheid, T.L. (Eds.), A Handbook for the Study of Mental Health. Cambridge University Press, Cambridge, England.

Wheaton, Blair, Young, Marisa, Montazer, Shirin, Stuart-Lahman, Katie, 2013. Social stress in the twenty-first century. In: Aneshensel, C.S., Phelan, J.C. Bierman, A. (Eds.), Handbook of the Sociology of Mental Health. Springer, New York, NY, pp. 299-324.

Wingfield, Adia Harvey, 2010. Are some emotions marked "Whites Only"? Racialized feeling rules in professional workplaces. Soc. Probl. 57 (2), 251-268.

Yamada, David C., 2008. Workplace Bullying and Ethical Leadership. Legal Studies Research Paper Series, Social Science Research Network. Available online at: http://ssin.com/abstract=1301554.

Yamada, David C., 2010. Workplace bullying and american employment law: a ten-year progress report and assessment. Comp. Labor Law Policy J. 32 (1), 251.

Zapf, Dieter, Einarsen, Ståle, 2001. Bullying in the workplace: recent trends in research and practice-an introduction. Eur. J. Work Organ. Psychol. 10 (4), 369-377. 